\title{
Household cleaning product-related ocular exposures reported to the United States poison control centres
}

\author{
Alisha Kamboj ${ }^{1,2} \cdot$ Henry A. Spiller ${ }^{2,3} \cdot$ Marcel J. Casavant $\mathbb{D}^{1,2,3} \cdot$ Sandhya Kistamgari ${ }^{1} \cdot$ Thitphalak Chounthirath $^{1} \cdot$ \\ Gary A. Smith $\mathbb{D}^{1,2,4}$
}

Received: 18 February 2019 / Revised: 26 October 2019 / Accepted: 4 November 2019 / Published online: 9 December 2019

(c) The Author(s), under exclusive licence to The Royal College of Ophthalmologists 2019

\begin{abstract}
Background/objectives To investigate ocular exposures associated with household cleaning products in the United States. Subjects/methods A retrospective analysis of ocular exposures associated with household cleaning products was conducted using data from the National Poison Data System from 2000 through 2016.

Results From January 2000 through December 2016, poison control centres in the United States received 319,508 calls for household cleaning product-related ocular exposures, averaging 18,795 exposures annually. The annual frequency of exposures decreased significantly by $28.8 \%$ during the study period. The rate of exposures per 100,000 US residents was 28.4 among young children ( $<6$ years), 4.8 among older children (6-12 years), 4.2 among teenagers (13-19 years), and 4.2 among adults ( $\geq 20$ years); children 2 years old had the highest rate of exposure (62.8). Bleaches (25.9\%), wall/floor/tile cleaners $(13.4 \%)$, disinfectants $(10.8 \%)$, laundry detergents $(6.1 \%)$, and glass cleaners $(5.3 \%)$ were the non-miscellaneous product subcategories most commonly associated with ocular exposures. The product subcategories associated with the greatest proportion of major medical outcomes were drain cleaners $(1.4 \%)$, oven cleaners $(1.1 \%)$, and automatic dishwasher detergents $(0.4 \%)$.

Conclusions On average, the United States poison control centres received approximately two reports of household cleaning product-related ocular exposures every hour during the 17-year study period. Although the annual number and rate of exposures declined during this time, the number of these exposures remains high, especially among young children, underscoring the need for additional prevention efforts. Contrary to the overall trend, ocular exposures to laundry detergent packets have increased significantly and merit special preventive action.
\end{abstract}

\section{Introduction}

Household cleaning products represent a major source of exposures reported to the United States (US) poison control centres (PCCs). These cleaning substances have ranked among the top three substance classes associated with

Gary A. Smith

gary.smith@nationwidechildrens.org

1 Center for Injury Research and Policy, The Research Institute at Nationwide Children's Hospital, 700 Children's Drive, Columbus, OH 43205, USA

2 The Ohio State University College of Medicine, Columbus, $\mathrm{OH}$, USA

3 Central Ohio Poison Center, Nationwide Children's Hospital, Columbus, $\mathrm{OH}$, USA

4 Child Injury Prevention Alliance, Columbus, OH, USA poisoning exposures since 2000. Since then, they have been linked to more than 190,000 cases reported to PCCs nationwide annually [1].

Exposures to household cleaning products commonly involve the eyes. In a study of exposures linked to cleaning products, $8.4 \%$ occurred as a result of eye contact [2]. Among children, this proportion may be even higher, with one investigation of paediatric cleaning product-related injuries citing eyes as the injured body region in nearly onefourth of cases [3, 4]. Ocular exposures to household cleaning products are associated with a wide spectrum of clinical effects, including eye pain, conjunctivitis, abnormal vision, chemical burns, and corneal ulcerations [2].

While previous research has broadly investigated injuries linked to cleaning agents and exposures to specific substances such as laundry detergent packets $[2,3,5,6]$, to our knowledge, this is the first comprehensive analysis of the US PCC data regarding eye exposures associated with household cleaning products. 


\section{Subjects and methods}

\section{Data source}

There are currently 55 regional PCCs that receive calls regarding substance exposures in the US, District of Columbia, and the US territories. These centres offer free, expert medical advice through the Poison Help Line $24 \mathrm{~h}$ per day, seven days a week. When responding to PCC calls, poison specialists document clinical findings associated with each case during consultation with the physician, patient, or patient's guardian. A subset of this information, which includes 131 clinical effects organized by organ system, is uploaded to the NPDS. Clinical effects listed under the "ocular" category include blurred vision, burns, corneal abrasion, irritation/pain, lacrimation, miosis, mydriasis, nystagmus, papilledema, photophobia, pupil(s) nonreactive, red eye/conjunctivitis, and visual defect. For each clinical effect, PCC specialists determine whether the effect is "related", "not related," or "unknown if related" to the exposure to the reported substance. Clinical effects are deemed "related" when the: "timing of the effect is reasonable for the reported exposure; severity of the effect is consistent with the reported exposure; effect is consistent with the anticipated substance toxicity; (or) clinical assessment of the relationship was made by a physician" [7]. When possible, PCC specialists continue to follow cases until the severity and duration of effects and outcomes are known, which may include throughout the course of the patient's hospitalization. Upon the completion of follow-up, PCC specialists classify cases into the medical outcome categories: no effect, minor effect, moderate effect, major effect, or death.

Data from exposures reported to PCCs are uploaded in near-real-time to the National Poison Data System (NPDS), a database maintained by the American Association of Poison Control Centers (AAPCC) that follows strict data quality control guidelines [7, 8]. This investigation retrospectively analysed ocular exposures associated with household cleaning products in the 50 US states and district of Columbia reported to the NPDS from January 1, 2000 through December 31, 2016.

\section{Case selection criteria}

NPDS data were obtained for all single-substance ocular exposures involving the major substance category of "cleaning substances (household)" from January 1, 2000 through December 31, 2016. The following were exclusion criteria for this study: (1) calls that originated outside the 50 US states or the District of Columbia $(n=2006)$; (2) medical outcomes categorized as confirmed non-exposure or unrelated effect $(n=1000)$; (3) reason for exposure documented as bite or sting, food poisoning, abuse, suspected suicide, adverse reaction to food, or withdrawal $(n=101)$; and (4) level of care coded as admitted to a psychiatric facility $(n=32)$. A total of 319,508 cases were included in study analyses.

\section{Study variables}

Study variables from the NPDS database included patient age and sex, product subcategory, year of exposure, state and site where exposure occurred, management site, level of health care received, medical outcome, clinical effects, and therapies.

Individuals were categorized as young children $(<6$ years), older children (6-12 years), teenagers (13-19 years), and adults ( $\geq 20$ years). States were grouped into regions (Northeast, Midwest, South, and West) as defined by the US Census Bureau [9]. Exposure sites were classified as residence (including patient's own residence and other residence), workplace, other (including health care facility (HCF), school, restaurant/food service, public area, and other), and unknown. The following AAPCC definitions of medical outcome were used: minor effect (symptoms are typically rapidly resolving and minimally bothersome); moderate effect (symptoms are more pronounced, prolonged, or systemic in nature than minor effect and usually necessitate some form of treatment); major effect (symptoms are life-threatening or result in significant residual disability or disfigurement) [7].

\section{Statistical analysis and ethical statement}

Statistical analysis was conducted using SPSS 21.0 (IBM Corp, Armonk, NY) and SAS 9.4 (SAS Institute, Inc., Cary, NC) software. Population-based rates were calculated using July 1 st intercensal and postcensal population estimates for 2000-2016 from the US Census Bureau [10]. Linear and piecewise regression was used to analyse secular trends, and the estimated slope $(\mathrm{m})$ from the regression model was reported, along with the associated $p$ value. Statistical significance was determined at $\alpha=0.05$. This study was judged exempt by the Institutional Review Board of the authors' institution.

\section{Results}

\section{General characteristics}

From January 2000 through December 2016, there were 319,508 calls to US PCCs regarding ocular exposures to household cleaning products, which equate to a mean of 18,795 exposures annually. The mean age of exposed individuals was 20.7 years (standard error of the mean $=$ 
Fig. 1 Number and rate of ocular exposures associated with household cleaning products by age, National Poison Data System 2000-2016. Exposures to individuals $>84$ years old are not shown because census data were not available for individuals $>84$ years old by single year of age; therefore, the rate per 100,000 US residents could not be calculated for individuals $>84$ years old

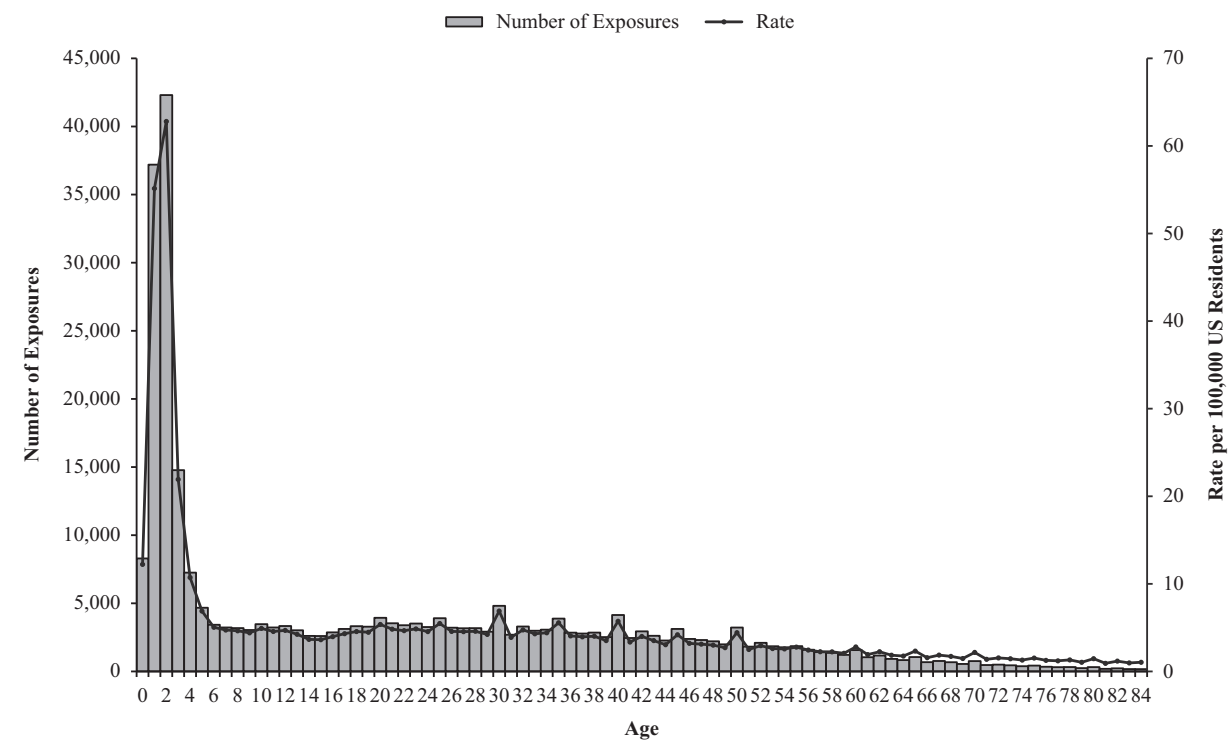

effects possible and $5.4 \%$ that were lost to follow-up. Among exposures that were followed to a known medical outcome, $6.4 \%$ resulted in no effects, $81.5 \%$ in minor effects, $11.9 \%$ in moderate effects, and $0.2 \%$ in major effects. Adults experienced the highest proportions of moderate $(10.4 \%)$ and major $(0.2 \%)$ effects. There were 398,879 related ocular clinical effects (some individuals had more than one clinical effect), and the most commonly reported ocular effects were ocular irritation or pain $(62.7 \%)$, red eye or conjunctivitis $(23.7 \%)$, lacrimation $(5.0 \%)$, blurred vision (3.4\%), and corneal abrasion $(2.8 \%)$.

Most $(61.4 \%)$ exposed individuals were managed onsite, while $36.6 \%$ were already in/en route to a $\mathrm{HCF}$ or referred to a HCF by the PCC (Table 1). Overall, $63.6 \%$ of exposures did not receive care at a $\mathrm{HCF}, 28.1 \%$ were treated/evaluated and released from a $\mathrm{HCF}$, and $0.3 \%$ were admitted to a HCF. A greater proportion (32.9\%) of adults was treated/evaluated and released than other age groups. The therapies utilized most frequently were dilution/irrigation/wash (92.0\%) and antibiotics (4.6\%).

\section{Product subcategories}

The product subcategory of bleaches was most commonly associated with ocular exposures, accounting for approximately one-fourth of exposures (25.9\%) (Table 2). Other non-miscellaneous product subcategories commonly associated with exposures included wall/floor/tile cleaners (13.4\%), disinfectants $(10.8 \%)$, laundry detergents $(6.1 \%)$, glass cleaners $(5.3 \%)$, and toilet bowl cleaners $(4.7 \%)$. Although bleaches represented the most common product subcategory among individuals 6 years of age and older, wall/floor/tile cleaners were most frequently (18.9\%) associated with exposures among young children. as nontoxic exposures or exposures with minimal clinical 
Table 1 Characteristics of ocular exposures associated with household cleaning products by age group, National Poison Data System 2000-2016

\begin{tabular}{|c|c|c|c|c|c|}
\hline \multirow[b]{2}{*}{ Characteristics } & \multicolumn{5}{|c|}{ Age group (years) } \\
\hline & $\begin{array}{l}<6 \\
n(\%)^{\mathrm{b}}\end{array}$ & $\begin{array}{l}6-12 \\
n(\%)^{\mathrm{b}}\end{array}$ & $\begin{array}{l}13-19 \\
n(\%)^{\mathrm{b}}\end{array}$ & $\begin{array}{l}\geq 20 \\
n(\%)^{\mathrm{b}}\end{array}$ & $\begin{array}{l}\text { Total }^{\mathrm{a}} \\
n(\%)^{\mathrm{b}}\end{array}$ \\
\hline \multicolumn{6}{|l|}{ Sex } \\
\hline Female & $44,359(38.7)$ & $10,746(46.5)$ & $10,073(47.5)$ & $105,118(67.1)$ & $172,046(54.0)$ \\
\hline Male & $70,395(61.3)$ & $12,358(53.5)$ & $11,129(52.5)$ & $51,596(32.9)$ & $146,576(46.0)$ \\
\hline Unknown & 217 & 72 & 24 & 247 & 886 \\
\hline \multicolumn{6}{|l|}{ Exposure site } \\
\hline Residence $^{\mathrm{d}}$ & $112,996(98.4)$ & $16,419(71.0)$ & $14,047(66.6)$ & $128,569(82.4)$ & $274,478(86.3)$ \\
\hline Workplace & $97(0.1)$ & $37(0.2)$ & $3234(15.3)$ & $24,335(15.6)$ & $28,045(8.8)$ \\
\hline School & $733(0.6)$ & $6132(26.5)$ & $3080(14.6)$ & $455(0.3)$ & $10,505(3.3)$ \\
\hline Other $^{\mathrm{e}}$ & $982(0.9)$ & $547(2.4)$ & $719(3.4)$ & $2621(1.7)$ & $5007(1.6)$ \\
\hline Unknown & 163 & 41 & 146 & 981 & 1473 \\
\hline \multicolumn{6}{|l|}{ Management site } \\
\hline Managed on-site (non-HCF) & $81,058(70.9)$ & $15,791(68.5)$ & $11,985(56.9)$ & $83,945(54.0)$ & $194,490(61.4)$ \\
\hline Patient already in/en route to $\mathrm{HCF}$ & $20,334(17.8)$ & $3079(13.4)$ & $4654(22.1)$ & $39,865(25.6)$ & $68,598(21.6)$ \\
\hline Patient was referred by PCC to a $\mathrm{HCF}$ & $12,153(10.6)$ & $2400(10.4)$ & $3349(15.9)$ & $29,245(18.8)$ & $47,600(15.0)$ \\
\hline Other & $799(0.7)$ & $1781(7.7)$ & $1059(5.0)$ & $2442(1.6)$ & $6163(1.9)$ \\
\hline Unknown & 627 & 125 & 179 & 1464 & 2657 \\
\hline \multicolumn{6}{|l|}{ Level of health care received } \\
\hline No $\mathrm{HCF}$ care received & $82,484(71.7)$ & $17,697(76.4)$ & $13,223(62.3)$ & $87,850(56.0)$ & $203,309(63.6)$ \\
\hline Treated/evaluated and released & $26,970(23.5)$ & $4324(18.7)$ & $6179(29.1)$ & $51,581(32.9)$ & $89,715(28.1)$ \\
\hline Admitted $^{\mathrm{f}}$ & $343(0.3)$ & $47(0.2)$ & $64(0.3)$ & $528(0.3)$ & $1003(0.3)$ \\
\hline Other ${ }^{g}$ & $5174(4.5)$ & $1108(4.8)$ & $1760(8.3)$ & $17,002(10.8)$ & $25,481(8.0)$ \\
\hline \multicolumn{6}{|l|}{ Medical outcome } \\
\hline No effect & $7809(6.8)$ & $1047(4.5)$ & $580(2.7)$ & $3,752(2.4)$ & $13,343(4.2)$ \\
\hline Minor effect & $65,503(57.0)$ & $13,060(56.4)$ & $11,655(54.9)$ & $79,384(50.6)$ & $170,868(53.5)$ \\
\hline Moderate effect & $5744(5.0)$ & $1058(4.6)$ & $1604(7.6)$ & $16,334(10.4)$ & $24,932(7.8)$ \\
\hline Major effect & $147(0.1)$ & $23(0.1)$ & $18(0.1)$ & $295(0.2)$ & $490(0.2)$ \\
\hline Not followed (minimal clinical effects possible) ${ }^{\mathrm{h}}$ & $31,878(27.7)$ & $7274(31.4)$ & $6172(29.1)$ & $46,183(29.4)$ & $92,582(29.0)$ \\
\hline $\begin{array}{l}\text { Unable to follow, judged as a potentially toxic } \\
\text { exposure }\end{array}$ & $3,890(3.4)$ & $714(3.1)$ & $1197(5.6)$ & $11,013(7.0)$ & $17,293(5.4)$ \\
\hline Total $(\text { row } \%)^{\mathrm{c}}$ & $114,971(36.0)$ & $23,176(7.3)$ & $21,226(6.6)$ & $156,961(49.1)$ & $319,508(100.0)$ \\
\hline
\end{tabular}

${ }^{\mathrm{a}}$ Total includes individuals with age group unknown

${ }^{\mathrm{b}}$ Column percentages may not sum to $100.0 \%$ due to rounding error

${ }^{c}$ Row percentages may not sum to $100.0 \%$ due to rounding error

dIncludes "own residence" and "other residence"

"Other includes "HCF," "restaurant/food service," "public area," and "other"

fAdmitted includes "admitted to critical care unit" and "admitted to noncritical care unit"

gOther includes "patient refused referral/did not arrive at HCF" and "patient lost to follow-up/left against medical advice"

${ }^{\mathrm{h}}$ Not followed (minimal clinical effects possible) includes "not followed (minimal clinical effects possible)" and "not followed, judged as nontoxic exposure"

Among all exposures followed to known medical outcomes, the product subcategories with the highest proportion of major effects were drain cleaners (1.4\%), oven cleaners $(1.1 \%)$, and automatic dishwasher detergents $(0.4 \%)$. Likewise, the product subcategories with the greatest proportion of moderate effects were oven cleaners (29.3\%), drain cleaners $(26.3 \%)$, and rust removers (19.2\%). In addition, the product subcategories with the highest proportion of minor effects were hand dishwashing products $(85.6 \%)$, bleaches $(84.2 \%)$, and fabric softeners/antistatic agents (83.7\%) (Table 2). 
Table 2 Ocular exposures associated with household cleaning products by product subcategory and medical outcome, National Poison Data System 2000-2016

\begin{tabular}{|c|c|c|c|c|c|}
\hline \multirow[t]{2}{*}{ Product subcategories/generic product names ${ }^{b}$} & \multirow[b]{2}{*}{$\begin{array}{l}\text { Total }^{\mathrm{a}} \\
n(\mathrm{col} . \%)^{\mathrm{c}}\end{array}$} & \multicolumn{4}{|c|}{ Exposures followed to known medical outcomes } \\
\hline & & $\begin{array}{l}\text { No effect } \\
n(\text { row } \%)^{\mathrm{d}}\end{array}$ & $\begin{array}{l}\text { Minor effect } \\
n(\text { row } \%)^{\mathrm{d}}\end{array}$ & $\begin{array}{l}\text { Moderate effect } \\
n(\text { row } \%)^{\mathrm{d}}\end{array}$ & $\begin{array}{l}\text { Major effect } \\
n(\text { row } \%)^{\mathrm{d}}\end{array}$ \\
\hline Bleaches & $82,599(25.9)$ & $2222(4.3)$ & $43,651(84.2)$ & $5893(11.4)$ & $64(0.1)$ \\
\hline Hypochlorite (liquid and dry) & $80,153(25.1)$ & $2127(2.7)$ & $42,390(52.9)$ & $5720(7.1)$ & $58(0.1)$ \\
\hline Miscellaneous Cleaners & $48,146(15.1)$ & $2186(6.9)$ & $25,436(80.0)$ & $4100(12.9)$ & $87(0.3)$ \\
\hline Miscellaneous cleaning agents: alkalis & $13,278(4.2)$ & $568(4.3)$ & $7049(53.1)$ & $1593(12.0)$ & $43(0.3)$ \\
\hline Miscellaneous cleaning agents: anionics or nonionics & $8689(2.7)$ & $361(4.2)$ & $4690(54.0)$ & $592(6.8)$ & $17(0.2)$ \\
\hline Miscellaneous cleaning agents: cationics & $6152(1.9)$ & $195(3.2)$ & $3034(49.3)$ & $771(12.5)$ & $15(0.2)$ \\
\hline $\begin{array}{l}\text { Miscellaneous cleaning agents: isopropanol (excluding automotive } \\
\text { products and glass) }\end{array}$ & $5831(1.8)$ & $323(5.5)$ & $3051(52.3)$ & $156(2.7)$ & $1(0.0)$ \\
\hline $\begin{array}{l}\text { Miscellaneous cleaning agents: other or unknown household } \\
\text { cleaning agents }\end{array}$ & $7987(2.5)$ & $434(5.4)$ & $4245(53.1)$ & $579(7.2)$ & $10(0.1)$ \\
\hline Wall/floor/tile cleaners & $42,841(13.4)$ & $2343(8.1)$ & $23,498(81.3)$ & $2990(10.3)$ & $64(0.2)$ \\
\hline Wall/floor/tile/all-purpose Cleaning agents: acids & $7717(2.4)$ & $437(5.7)$ & $4609(59.7)$ & $517(6.7)$ & $13(0.2)$ \\
\hline Wall/floor/tile/all-purpose cleaning agents: alkalis & $17,953(5.6)$ & $961(5.4)$ & $9651(53.8)$ & $1404(7.8)$ & $33(0.2)$ \\
\hline Wall/floor/tile/all-purpose cleaning agents: anionics or nonionics & $6616(2.1)$ & $329(5.0)$ & $3530(53.4)$ & $546(8.3)$ & $5(0.1)$ \\
\hline Wall/floor/tile/all-purpose cleaning agents: cationics & $4680(1.5)$ & $236(5.0)$ & $2427(51.9)$ & $218(4.7)$ & $4(0.1)$ \\
\hline Disinfectants & $34,591(10.8)$ & $1,508(6.9)$ & $18,174(82.7)$ & $2263(10.3)$ & $41(0.2)$ \\
\hline Disinfectants: hypochlorite (non-bleach products) & $13,820(4.3)$ & $395(2.9)$ & $6749(48.8)$ & $1207(8.7)$ & $20(0.1)$ \\
\hline Disinfectants: other or unknown & $14,273(4.5)$ & $781(5.5)$ & $7895(55.3)$ & $697(4.9)$ & $10(0.1)$ \\
\hline Disinfectants: phenol & $3110(1.0)$ & $170(5.5)$ & $1763(56.7)$ & $145(4.7)$ & $7(0.2)$ \\
\hline Disinfectants: pine oil & $3388(1.1)$ & $162(4.8)$ & $1767(52.2)$ & $214(6.3)$ & $4(0.1)$ \\
\hline Laundry detergents & $19,338(6.1)$ & $440(3.4)$ & $10,398(80.8)$ & $1983(15.4)$ & $41(0.3)$ \\
\hline Laundry detergents: granules (various containers) & $6258(2.0)$ & $173(2.8)$ & $3493(55.8)$ & $401(6.4)$ & $7(0.1)$ \\
\hline Laundry detergents: liquids (unit dose) & $5020(1.6)$ & $94(1.9)$ & $2745(54.7)$ & $778(15.5)$ & $20(0.4)$ \\
\hline Laundry detergents: liquids (various containers) & $7502(2.3)$ & $156(2.1)$ & $3854(51.4)$ & $737(9.8)$ & $13(0.2)$ \\
\hline Glass cleaners & $16,825(5.3)$ & $1497(13.7)$ & $8961(82.1)$ & $452(4.1)$ & $4(0.0)$ \\
\hline Glass cleaners: ammonia containing & $8833(2.8)$ & $880(10.0)$ & $4737(53.6)$ & $181(2.0)$ & $2(0.0)$ \\
\hline Glass cleaners: isopropanol & $4894(1.5)$ & $363(7.4)$ & $2587(52.9)$ & $144(2.9)$ & $2(0.0)$ \\
\hline Toilet bowl cleaners & $14,911(4.7)$ & $517(4.7)$ & $8937(81.8)$ & $1450(13.3)$ & $19(0.2)$ \\
\hline Toilet bowl cleaners: acids & $8845(2.8)$ & $287(3.2)$ & $5665(64.0)$ & $932(10.5)$ & $10(0.1)$ \\
\hline Toilet bowl cleaners: alkalis & $4082(1.3)$ & $148(3.6)$ & $2223(54.5)$ & $363(8.9)$ & $6(0.1)$ \\
\hline Laundry prewash/stain removers & $13,324(4.2)$ & $681(7.3)$ & $7481(80.5)$ & 1103 (11.9) & $23(0.2)$ \\
\hline Laundry prewash/stain removers: liquid surfactant based & $4458(1.4)$ & $204(4.6)$ & $2406(54.0)$ & $491(11.0)$ & $10(0.2)$ \\
\hline Laundry prewash/stain removers: other or unknown & $5665(1.8)$ & $303(5.3)$ & $3273(57.8)$ & $301(5.3)$ & $7(0.1)$ \\
\hline Miscellaneous cleaning substances (household) & $9050(2.8)$ & $574(9.7)$ & $4879(82.2)$ & $468(7.9)$ & $11(0.2)$ \\
\hline Carpet, upholstery, leather, or vinyl cleaners & $6326(2.0)$ & $8(0.0)$ & $3478(1.1)$ & $304(0.1)$ & $416(0.1)$ \\
\hline Hand dishwashing & $7312(2.3)$ & $176(3.8)$ & $4013(85.6)$ & $491(10.5)$ & $7(0.1)$ \\
\hline Anionic or nonionic hand dishwashing detergents & $5511(1.7)$ & $135(2.4)$ & $3091(56.1)$ & $369(6.7)$ & $7(0.1)$ \\
\hline Oven cleaners & $5968(1.9)$ & $183(4.4)$ & $2691(65.1)$ & $1210(29.3)$ & $47(1.1)$ \\
\hline Oven cleaners: alkalis & $5203(1.6)$ & $161(3.1)$ & $2358(45.3)$ & $1083(20.8)$ & $41(0.8)$ \\
\hline Cleansers & $5712(1.8)$ & $287(7.8)$ & $2942(79.5)$ & $466(12.6)$ & $7(0.2)$ \\
\hline Other types/unknown household cleaners & $3532(1.1)$ & $177(5.0)$ & $1762(49.9)$ & $330(9.3)$ & $6(0.2)$ \\
\hline Drain cleaners & $5401(1.7)$ & $158(4.3)$ & $2474(68.0)$ & $957(26.3)$ & $50(1.4)$ \\
\hline Drain cleaners-alkalis & $4009(1.3)$ & $104(2.6)$ & $1807(45.1)$ & $736(18.4)$ & $43(1.1)$ \\
\hline Automatic dishwasher detergents & $5201(1.6)$ & $140(4.1)$ & $2782(80.8)$ & $505(14.7)$ & $14(0.4)$ \\
\hline Spot removers/dry cleaning agents & $2820(0.9)$ & $149(8.1)$ & $1538(83.2)$ & $160(8.7)$ & $2(0.1)$ \\
\hline Laundry additives & $2412(0.8)$ & $145(9.1)$ & $1324(82.6)$ & $128(8.0)$ & $5(0.3)$ \\
\hline Rust removers & $1855(0.6)$ & $61(4.5)$ & $1033(76.0)$ & $261(19.2)$ & $4(0.3)$ \\
\hline Fabric softeners/antistatic agents & $1202(0.4)$ & $76(9.7)$ & $656(83.7)$ & $52(6.6)$ & $0(0.0)$ \\
\hline Total & $319,508(100.0)$ & $13,343(6.4)$ & $170,868(81.5)$ & $24,932(11.9)$ & $490(0.2)$ \\
\hline
\end{tabular}

aTotal includes exposures with medical outcomes of "not followed (minimal clinical effects possible)" and "unable to follow, judged as a potentially toxic exposure"

${ }^{\mathrm{b}}$ Selected generic products were included if they accounted for $\geq 1 \%$ of all exposures

${ }^{\mathrm{c}}$ Column percentages were calculated using the total number of exposures as the denominator

${ }^{\mathrm{d}}$ Row percentages for each product were calculated using only the total number of exposures followed to a known medical outcome 


\section{Secular trends}

During the 17-year study period, the annual number and rate of ocular exposures decreased significantly by $28.8 \%$ $(m=-600.1, \quad p<0.001)$ and $37.8 \%(m=-0.25, \quad p<$ 0.001 ), respectively (Fig. 2). This decrease in the number and rate of exposures was consistent across all age groups except children $<6$ years old, with the largest decrease in the number of exposures observed among teenagers 13-19 years old ( $45.3 \%$ decrease, $m=-68.2, p<0.001)$, followed by older children $6-12$ years old $(42.9 \%$ decrease, $m=$ $-65.7, p<0.001)$ and adults $(25.9 \%$ decrease, $m=-265.0$, $p<0.001)$. Among children $<6$ years old, the number of exposures decreased significantly from 2000 to 2011 (41.6\% decrease, $m=-330.8, p<0.001$ ) prior to a significant increase of $27.8 \%$ from 2011 to 2016 ( $m=230.0$, $p=0.001)$. Secular trends for study variables were similar among regions, with the exception of the number of admissions to a HCF. For this variable, the Southern region, when compared with other regions, demonstrated a large increase during the study period; however, the annual number of admissions was relatively small.

Most product subcategories exhibited statistically significant decreases in exposure frequency from 2000 to 2016. Among these, the non-miscellaneous product subcategories that exhibited the greatest decreases were glass cleaners $(76.9 \%$ decrease, $m=-92.6, p<0.001)$, spot removers $(65.2 \%$ decrease, $m=-11.7, p<0.001)$, and oven cleaners (32.4\% decrease, $m=-10.8, p<0.001)$. Exposures associated with wall/floor/tile cleaners increased by $28.0 \%$ from 2000 to 2004 ( $m=49.3, p=0.453)$ before decreasing significantly by $48.6 \%(m=-139.4, p<0.001)$ from 2004 to 2016 . The trend for laundry detergent exposures was downward from 2000 to 2011 (41.7\% decrease, $m=-31.2, p=0.004)$ before an increase of $287.1 \%(m=$ 374.5, $p<0.001$ ) from 2011 to 2016 (Fig. 3). This
Fig. 2 Rate of ocular exposures associated with household cleaning products by age group and by year, National Poison Data System 2000-2016
Fig. 3 Number of ocular exposures associated with the five household cleaning products most commonly associated with ocular exposure by year, National Poison Data System 2000-2016
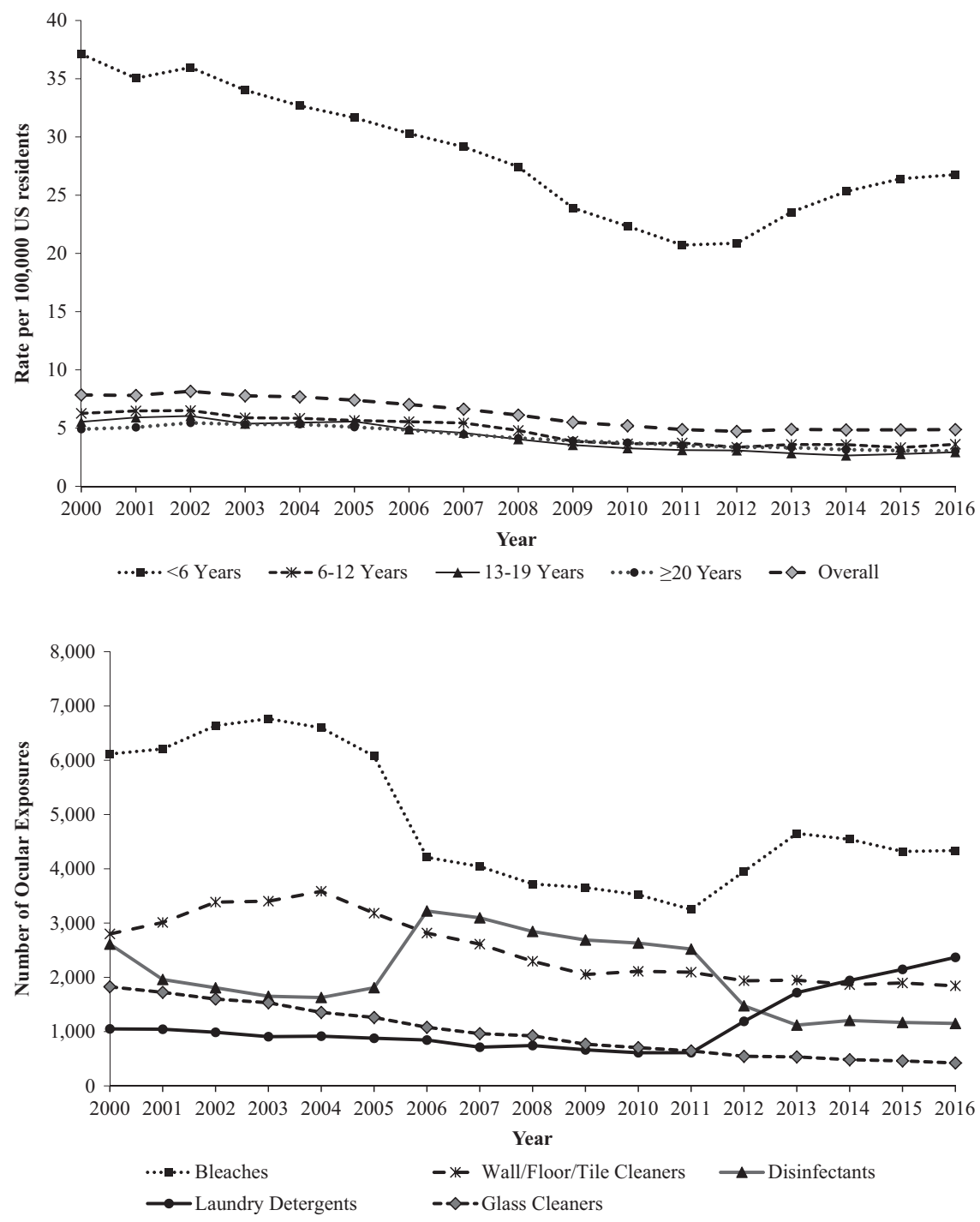
represented an overall increase of $125.6 \%$ between 2000 and 2016, which is contrary to the decreasing trend seen for most product subcategories. This increase was mainly driven by laundry detergent packet-related ocular exposures, which increased significantly by $1959.7 \%(m=415.2, p<$ 0.001) from 2012 to 2016; the number of exposures associated with other types of laundry detergents remained relatively constant $(m=20.4, p=0.532)$ during that period. The secular trends in the annual number of ocular exposures for the five most commonly associated household cleaning products are shown in Fig. 3.

\section{Discussion}

Household cleaning products resulted in an average of almost 19,000 ocular exposures reported to the US PCCs annually, or about two exposures per hour. The annual number of exposures decreased significantly by $28.8 \%$ from 2000 through 2016, which is consistent with previous reports of exposures to household cleaning products as well as studies of eye injuries [3, 11, 12]. The Poison Prevention Packaging Act of 1970, which requires child-resistant packaging for a variety of household substances, has played an important role in the decline in paediatric poisoning during the decades that followed its enactment [13]. Under this law, child-resistant closures are mandated for many hazardous cleaning products, such as furniture polish, drain cleaners, oven cleaners, and rust removers. More recent advances in prevention practices and increased public awareness about the hazards of household cleaning substances may have contributed to the observed decrease in ocular exposures.

Despite these efforts, young children continue to be the age group with the highest rate of ocular exposure to household cleaning substances. In this study, children 2 years of age experienced the highest rate of exposure. A number of factors likely contribute to exposure risk at this age, including a large amount of time spent in the home, newfound mobility, curiosity for unfamiliar and intriguing external stimuli, and an inability to recognize potential danger [14]. Cleaning products may be particularly alluring to young children due to their colourful packaging and contents as well as unique scents. Access to these products may occur when child-resistant closures are inadequately sealed, container integrity is compromised from repeated use, or containers are stored in an unsafe manner [15]. A study of poisoning exposures among 11-18 month-old toddlers revealed that the proportion of cleaning substances stored unsafely-defined in the study as not stored in a locked cupboard or at adult eye level or above-was $27.9 \%$, $15.0 \%$, and $11.4 \%$ in the kitchen, bathroom, and garage or shed, respectively. Households with only one child or a child who was not yet able to walk independently had a higher likelihood of unsafe storage practices [16].

The product subcategory most frequently associated with ocular exposures was bleaches, accounting for approximately one-fourth of exposures in this study. This finding is concordant with other studies that identify bleach as the most commonly implicated household cleaning product in paediatric ingestions [3, 17]. Other product subcategories commonly implicated in this study were wall/floor/tile cleaners, disinfectants, laundry detergents, glass cleaners, and toilet bowl cleaners. The high frequency of exposures linked to these substances may, in part, be attributed to their prevalence in the home and their accompanying storage strategies. For example, a prior study of households in which a child younger than 5 years resided noted disinfectants/antiseptic agents and bleaches to be present in 90 and $75 \%$ of homes, respectively [18]. Moreover, among a list of hazardous household substances, bleach and toilet bowl cleaners were observed to be among the least likely to be stored safely. Finally, perceived toxicity of specific products by parents may influence poison prevention practices and care-seeking behaviours in the event of a child exposure [19].

Since their introduction into the US market in 2012, laundry detergent packets have been associated with a plethora of unintentional poisoning exposures and have gained additional notoriety for their recent association with the social media phenomenon known as the "Tide Pod Challenge" [20-22]. Young children, in particular, may rupture the packets, resulting in ingestions as well as dermal and ocular exposures. From 2012 through 2013, PCCs nationwide received more than 17,000 reports of laundry detergent packet exposures among children $<6$ years of age. Among the spectrum of associated clinical effects, the most commonly observed ocular sequelae included irritation or pain, red eye or conjunctivitis, lacrimation, corneal abrasion, and burns [5]. In our study, the product subcategory of laundry detergents was the only one that exhibited a statistically significant overall increase in exposure frequency, with this increase starting in 2012. While the number of laundry detergent packet-related ocular exposures increased from 2012 through 2016, the number associated with other types of laundry detergents remained relatively constant, emphasizing the urgent need to increase prevention efforts that target laundry detergent packets.

The product subcategories associated with the greatest proportion of major effects were drain cleaners and oven cleaners. Drain cleaners and oven cleaners typically have $\mathrm{pH}$ values of 12 or higher; the presence of a strong base, often sodium hydroxide, in these substances facilitates the disruption of bonds in oil or grease of animal and plant origin [23]. Due to their alkaline nature, these substances are able to penetrate ocular tissues more rapidly and deeply 
than acids and may cause significant damage to the cornea, iris, ciliary body, and lens [24-26]. Sequelae of chemical eye exposures may be severe, with the potential for significant visual impairment or disfigurement.

\section{Prevention}

Prevention efforts should be prioritized for children $<6$ years of age because this age group has an ocular exposure rate to household cleaning products that is more than 6 times higher than that of other age groups. Utilization of child-resistant containers, safe storage of potentially hazardous products in locations that are out of the reach and sight of young children, and caution when using these products around young children are useful strategies to prevent unintentional ocular exposures as well as ingestions in this age group. Increased adoption of flow resistors on liquid containers may have a role in limiting eye exposures and ingestions. Improved burst resistance and individual wrapping of laundry detergent packets may help prevent ocular exposure to the contents of these products. Increased public awareness about risks to ocular health as well as prevention and treatment options may help reduce the frequency and associated morbidity of ocular exposures. Manufacturer participation is crucial to ensure the integrity and effectiveness of child-resistant closures, pursue reformulation of products (when possible) to reduce the hazard, and modify packaging to decrease attractiveness to young children. Finally, ongoing involvement of health professionals, policy makers, and others is essential to promote the continued decline in ocular exposures associated with household cleaning products.

\section{Study limitations}

This study underestimates the actual number of ocular exposures associated with household cleaning products in the US because NPDS data are voluntarily reported. As a result, this database does not include exposures that did not result in a call to a PCC for reasons such as lack of awareness of PCC resources, failure to seek care, or receipt of medical care directly from a HCF or other provider without a call to a PCC. However, previous research showed that the reported number of paediatric pharmaceutical ingestion cases was similar for the NPDS and a national emergency department surveillance system, which supports the validity of NPDS data [27]. Although PCC professionals adhere to strict protocols for following and documenting exposures, the accuracy and completeness of the information included in the NPDS cannot be fully verified by PCCs or the AAPCC. Imprecision may also arise from miscoding by PCC specialists. Despite these limitations, the NPDS is a high-quality national data source for the investigation of ocular exposures associated with household cleaning substances in the US.

\section{Summary}

\section{What was known before}

- Exposure to household cleaning products commonly involves the eyes, especially among children.

- Ocular exposures to household cleaning products are associated with a wide spectrum of clinical effects.

\section{What this study adds}

- From January 2000 through December 2016, poison control centres in the United States received 319,508 calls for household cleaning product-related ocular exposures, averaging 18,795 exposures annually. Children 2 years of age had the highest rate of exposure (62.8 exposures per 100,000 United States residents).

- The annual frequency of ocular exposures to household cleaning products decreased significantly by $28.8 \%$ from 2000 to 2016; however, contrary to this overall trend, ocular exposures to laundry detergent packets increased significantly by $1960 \%$ from 2012 to 2016 .

- Product subcategories associated with the greatest proportion of major medical outcomes were drain cleaners, oven cleaners, and automatic dishwasher detergents.

\section{Compliance with ethical standards}

Conflict of interest The authors declare that they have no conflict of interest.

Publisher's note Springer Nature remains neutral with regard to jurisdictional claims in published maps and institutional affiliations.

\section{References}

1. American Association of Poison Control Centers. National poison data system annual reports. Alexandria, VA, USA, 2016. http://www.aapcc.org/annual-reports/. Accessed 5 Feb 2018.

2. Williams H, Moyns E, Bateman DN, Thomas SH, Thompson JP, Allister Vale J. Hazard of household cleaning products: a study undertaken by the UK national poisons information service. Clin Toxicol. 2012;50:770-5.

3. McKenzie LB, Ahir N, Stolz U, Nelson NG. Household cleaning product-related injuries treated in US emergency departments in 1990-2006. Pediatrics. 2010;126:509-16.

4. Franklin RL, Rodgers GB. Unintentional child poisonings treated in United States hospital emergency departments: national 
estimates of incident cases, population-based poisoning rates, and product involvement. Pediatrics. 2008;122:1244-51.

5. Valdez AL, Casavant MJ, Spiller HA, Chounthirath T, Xiang H, Smith GA. Pediatric exposure to laundry detergent pods. Pediatrics. 2014;134:1127-35.

6. Huntington S, Heppner J, Vohra R, Mallios R, Geller RJ. Serious adverse effects from single-use detergent sacs: report from a U.S. statewide poison control system. Clin Toxicol. 2014;52:220-5.

7. American Association of Poison Control Centers. National poison data system (NPDS): NPDS system manual. Alexandria, VA, USA, 2009. http://www.aapcc.org/data-system/. Accessed 5 Feb 2018.

8. Wolkin AF, Martin CA, Law RK, Schier JG, Bronstein AC. Using poison center data for national public health surveillance for chemical and poison exposure and associated illness. Ann Emerg Med. 2012;59:56-61.

9. US Census Bureau. Geographic terms and concepts-Census divisions and census regions. Suitland, MD, USA, 2015. https://www2.census.gov/geo/docs/maps-data/maps/reg_div.txt. Accessed 5 Feb 2018.

10. US Census Bureau. Population and housing unit estimates datasets. Suitland, MD, USA, 2017. https://www.census.gov/programssurveys/popest/data/data-sets.All.html\%0D. Accessed $5 \mathrm{Feb}$ 2018.

11. Pollard KA, Xiang H, Smith GA. Pediatric eye injuries treated in US emergency departments, 1990-2009. Clin Pediatr (Phila). 2012;51:374-81.

12. McGwin G Jr., Hall TA, Xie A, Owsley C. Trends in eye injury in the United States, 1992-2001. Investig Ophthalmol Vis Sci. 2006;47:521-7.

13. Walton WW. An evaluation of the Poison Prevention Packaging Act. Pediatrics. 1982;69:363-70. http://pediatrics.aappublications. org/content/69/3/363.full.pdf\%5Cn, http://www.ncbi.nlm.nih.gov/ pubmed/7063294.

14. Centers for Disease Control and Prevention. Developmental Milestones. Atlanta, GA, USA, 2017. https://www.cdc.gov/ ncbddd/actearly/milestones/index.html. Accessed 5 Feb 2017.
15. Bertinelli A, Hamill J, Mahadevan M, Miles F. Serious injuries from dishwasher powder ingestions in small children. J Paediatr Child Health. 2006;42:129-33.

16. Beirens TMJ, van Beeck EF, Dekker R, Brug J, Raat H. Unsafe storage of poisons in homes with toddlers. Accid Anal Prev. 2006;38:772-6.

17. Harley EH, Collins MD. Liquid household bleach ingestion in children: a retrospective review. Laryngoscope. 1997;107:122-5.

18. Ashby K, Routley V. Childhood domestic chemical and plant poisonings. Hazard. 1996;28:1-16.

19. Patel B, Groom L, Prasad V, Kendrick D. Parental poison prevention practices and their relationship with perceived toxicity: cross-sectional study. Inj Prev. 2008;14:389-95.

20. Davis MG, Casavant MJ, Spiller HA, Chounthirath T, Smith GA. Pediatric exposures to laundry and dishwasher detergents in the United States: 2013-2014. Pediatrics. 2016;137:5.

21. Swain TA, McGwin G, Griffin R. Laundry pod and non-pod detergent related emergency department visits occurring in children in the USA. Inj Prev. 2016;22:396-9.

22. Ducharme J. Here's how common the tide pod challenge really is. Time. New York City, NY, USA, 2018. http://time.com/5104225/ tide-pod-challenge/. Accessed 3 Mar 2018.

23. Hogg JL. Acid-Base Reactions. In: CHEM2: Chemistry in Your World. 2nd ed. Brooks Cole Cengage Learning: Boston, MA, USA, 2014. p. 167.

24. Grant WM. Description of toxic substances and their effects on the eyes. In: Charles CT, editor. Toxicology of the Eye. Charles Thomas Publisher Ltd: Springfield, IL, USA, 1962, pp 17-22.

25. Morgan SJ. Chemical burns of the eye: causes and management. Br J Ophthalmol. 1987;71:854-7.

26. Singh P, Tyagi M, Kumar Y, Gupta K, Sharma P. Ocular chemical injuries and their management. Oman J Ophthalmol. 2013;6: 83-6.

27. Setlik J, Ho M, Bond GR. Emergency department use after pediatric pharmaceutical ingestion: comparison of two national databases. Clin Toxicol. 2010;48:64-7. 